\title{
A comparison of asthma deaths and near-fatal asthma attacks in South Australia
}

\author{
D.A. Campbell*, G. McLennan**, J.R. Coates***, P.A. Frith+, \\ P.A. Gluyas*, K.M. Latimer ${ }^{++}$, C.G. Luke ${ }^{++}$, A.J. Martin\$, D.M. Roder\$, \\ R.E. Ruffin*, P.M. Yellowlees
}

A comparison of asthma deaths and near-fatal asthma attacks in South Australia. D.A. Campbell, G. McLennan, J.R. Coates, P.A. Frith, P.A. Gluyas, K.M. Latimer, C.G. Luke, A.J. Martin, D.M. Roder, R.E. Ruffin, P.M. Yellowlees. CERS Journals Ltd 1994.

ABSTRACT: Studies seeking to identify factors predictive of asthma mortality have relied on information obtained from relatives, other close acquaintances, and doctors who cared for the deceased. We wanted to determine whether asthmatics who have suffered a near-fatal asthma attack (NFA) are similar to asthmatics who have died of asthma with respect to important features, because studies of NFA asthmatics may provide a better insight into causes of asthma death. Such studies would avoid the difficulties associated with seeking information secondhand from proxy informants.

Two groups were studied: asthmatics who had suffered a near-fatal asthma attack resulting in a visit to the accident and emergency departments of teaching hospitals $(n=154)$, and asthmatics certified as dying of asthma who, following panel review, were confirmed to have died from this disease $(n=80)$. For each case in the two groups, an interview questionnaire was administered to a close acquaintance (household or family member) and to the general practitioner.

Both groups shared many important characteristics. Similarities related to: frequency of symptoms; frequency of hospital and intensive care unit admissions for asthma; use of asthma crisis plans; compliance with prescribed medications; quality of personal asthma management; and asthma severity. The two groups also showed similar psychiatric profiles, and similar use of asthma medications on a regular basis and with increased symptoms. However, NFA cases tended to be younger, were more likely to be male, and less likely to have concurrent medical conditions. Where the final episode was considered definitely or probably preventable, NFA cases were less likely to have experienced delay in actually receiving medical care, and were found to have had more ready access to acute medical care.

Eur Respir J., 1994, 7, 490-497.
*Thoracic Medicine Unit, The Queen Elizabeth Hospital, Woodville South, South Australia. **Dept of Thoracic Medicine, Royal Adelaide Hospital, Adelaide, South Australia. ***Royal Australian College of General Practitioners (South Australia Faculty), North Adelaide, South Australia. ${ }^{+}$Respiratory Unit, Repatriation General Hospital, Daw Park, South Australia. ${ }^{++}$Respiratory Unit, Flinders Medical Centre, Bedford Park, South Australia. ${ }^{+++}$Clinical Epidemiology Unit, The Queen Elizabeth Hospital, Woodville South, South Australia. \$Paediatric Pulmonology Unit, Adelaide Children's Hospital, North Adelaide, South Australia. ${ }^{\$}$ Epidemiology Branch, South Australian Health Commission, Adelaide, South Australia. †'South Australian Mental Health Service, Felixstowe, South Australia.

Correspondence: D.A. Campbell, Thoracic Medicine Unit, The Queen Elizabeth Hospital, Woodville Road, Woodville South, South Australia 5011, Australia.

Keywords: Asthma, epidemiology, mortality, near-fatal, psychiatry.

Received: March 30 1993; accepted after revision October 231993
Certified asthma death rates increased markedly in Australia in the 10 yrs to 1988 [1]. Meanwhile, a number of studies have identified high levels of potentially preventable or avoidable factors associated with asthma mortality [2-5], including deficiencies in professional and self-management characteristics. YellowleEs and RUFFIN [6] also found high levels of psychiatric disorders, including denial and anxiety, among individuals experiencing near-fatal attacks of asthma. REA et al. [5] indicated the importance of a history of a previous near-fatal asthma attack as a risk factor for subsequent death due to asthma. This observation raise, the question of whether asthmatics who suffer near-fatal attacks (NFAs) are similar in many respects to those who die of asthma.

If it can be shown that NFA cases are similar to asthma death cases with regard to asthma severity, quality of personal, self-management and psychosocial characteristics, and other features, then broader descriptive studies of NFA cases may yield a better characterization of asthmatic subjects at risk of fatal asthma, and reveal opportunities for preventive intervention. Such studies would not encounter the difficulties found in death studies, where detailed information cannot be obtained directly from subjects.

A principal objective of the present study was to test whether patients dying of asthma and asthmatics experiencing NFAs were similar with regard to: their personal and psychiatric characteristics; the history and severity of their asthma; features of medical and personal management; circumstances surrounding the fatal or near-fatal episode; and whether the episode could have been prevented.

\section{Methods}

The State of South Australia has a population of over 1.4 million people, of whom more than one million reside in the capital city, Adelaide. The study period was from 
May, 1988 to June, 1991. Persons dying in South Australia during this period were enrolled in the study if "asthma", "asthmatic" or "status asthmaticus" was recorded in Part I or II of the death certificate. The death certificates were reviewed by a panel comprising six respiratory physicians, a general practitioner and a research assistant (a registered nurse). If, following this review, the panel considered that the death may have been due to asthma, the certifying doctor was interviewed concerning the circumstances surrounding the death. This applied for $89 \%$ of cases. Except where certifying doctors provided clear and compelling evidence that asthma was not the cause of death, interviews were held with the subjects' general practitioners, allied health professionals and household or other close acquaintances. This normally occurred within three months of the death. Close acquaintances were not available for interview in three instances, and declined to participate on five other occasions. Of the 165 deceased cases where interviews of close acquaintances and medical practitioners were possible (95\%), the panel concluded that 80 were "definite" asthma deaths, and the remainder were either not due to asthma or the role of asthma was uncertain. Only data for the 80 "definite" asthma deaths are presented here.

During the same period, NFA cases visiting the accident and emergency departments of Adelaide teaching hospitals were recruited. To be eligible for entry into the study, cases had to have experienced asthma resulting in either respiratory arrest, or an arterial carbon dioxide tension $\left(\mathrm{PaCO}_{2}\right)$ above $50 \mathrm{mmHg}(6.7 \mathrm{kPa})$, and/or an altered conscious state or inability to speak on presentation to hospital [6]. Of the 158 eligible cases identified during the study period, $154(97 \%)$ agreed to participate. To obtain comparable data for both the deceased and NFA cases, and to avoid measurement bias in the comparisons, interviews of an identical format to those for death cases were held with household or other close acquaintances and general medical practitioners, as a prelude to case review by the assessment panel. The reliability of data obtained directly from household and other close acquaintances, when compared with data obtained from cases suffering near-fatal asthma attacks, has been described previously [7].

The interview questionnaire used in previous surveys of asthma mortality in New Zealand and Victoria was used [2, 3]. The questionnaire contained sections on personal details, previous asthma symptoms and management, and circumstances surrounding the final event. Additional items concerning psychiatric characteristics were added. These included history of personal and family psychiatric treatment, the denial scale of the Illness Behaviour Questionnaire [8], and the General Health Questionnaire (GHQ)-28 [9], which measures psychiatric caseness.

A diagnosis of asthma was accepted if the subject's general practitioner reported that he/she had asthma, and one of the following conditions was present: 1) subjective evidence of variable wheeze and/or breathlessness and a response to asthma treatment; 2) objective evidence of $20 \%$ reversibility in peak expiratory flow recordings, or forced expiratory volume in one second $\left(\mathrm{FEV}_{1}\right)$ by spirometry (with $200 \mathrm{ml}$ incremental improvement following bronchodilator administration); and 3) autopsy evidence of asthma, including epithelial shedding, eosinophil infiltration in the walls of small airways and thickening of the basement membrane.

All reported information was reviewed by the assessment panel, which made collective judgements based on the professional backgrounds of members. The presence of psychosocial features which may have contributed to the asthma episode was assessed from reported evidence of psychiatric illness, drug abuse, social isolation, intellectual handicap or denial of asthma severity. Judgements concerning the severity of the asthma, and the likelihood that asthma caused the final episode, were made according to criteria established prior to study commencement. Asthma severity in the 12 months prior to the fatal or near-fatal episode was classified as mild, moderate or severe, based on reported symptoms, exercise capacity, medication requirements and frequency of attacks, and utilization of medical services for asthma episodes, as described by ROBERTSON et al. [2]. Assessments were made concerning the quality of self-management and the appropriateness of, and compliance with, prior therapy; and whether the subject had been provided with an action plan specifying the actions to be taken in the event of deteriorating asthma control. Finally, an assessment was made concerning the preventability of the episode and whether end-stage asthma was present.

It was recognized from the outset that panel assessments of many items would be highly subjective. Attempts were made to reduce the potential for bias by undertaking panel assessments of death and NFA cases in haphazard order, and by using a highly structured assessment process. Because respondents were often insufficiently wellinformed to respond, the numbers of responses (n) varied for individual items. These numbers are specified with the results.

\section{Analysis}

Univariate comparisons of death and NFA data were undertaken using the Mann-Whitney U-test for ordinal variables, and the conventional Chi-squared test for polychotomous nominal and dichotomous variables [10]. Fisher's exact test was substituted when $2 \times 2$ tables yielded expected values of less than five [11]. Because death and NFA cases were found to vary by age and sex, unconditional logistic regression was undertaken when univariate tests produced $p$ values towards the lower end of the scale $(p<0.25)[12,13]$. The purpose was to test whether individuals' features were predictive of membership of the death or NFA group after adjusting for age and sex. To improve model fit, age was treated as three dummy variables, i.e. 20-39, 40-59 and $\geq 60$ yrs, respectively, with $0-19$ year olds as the reference category. All models were examined for goodness of fit and collinearity among predictors, and were found to fit the data well, with little evidence of ill-conditioning [14]. Throughout the results section, it should be noted that reference to regression analysis pertains to logistic regression, where age and sex were entered together with the feature of specific interest. 


\section{Results}

\section{Personal characteristics}

For age and sex. Death cases $(\mathrm{n}=80)$ were older than the NFA cases $(n=154)$, the mean $( \pm$ SEM) ages being 52 $( \pm 2.4)$ and $36( \pm 1.8)$ yrs, respectively. There was also a difference by $\operatorname{sex}\left(\chi^{2}{ }_{(1)}=6.4 ; p=0.011\right)$, with males comprising $39 \%$ of deaths and $57 \%$ of NFA cases. Age and sex were found to be independent predictors in the logistic regression $(\mathrm{p}<0.001$ and $\mathrm{p}=0.010$, respectively).

Searching for psychosocial factors. There was no significant difference between the $22 \%$ of death cases $(n=63)$ and $17 \%$ of NFA cases $(n=121)$ who had a history of psychiatric consultation $(\mathrm{p}=0.457)$, or between the $21 \%(\mathrm{n}=58)$ and $14 \%(n=119)$, respectively, where a past psychiatric history was obtained for a first-degree family member $(\mathrm{p}=0.388)$.

Mean denial scores for subjects aged 15 yrs or more were 3.1 for death cases $(n=58)$ and 3.4 for NFA cases $(n=96)$, with high scores of three or more being more common among NFA cases (74\%) than death cases $(55 \%)$ $\left(\chi_{(1)}^{2}=4.9 ; \mathrm{p}=0.026\right)$. Regression analysis showed this latter difference to be significant after age-sex adjustment $(\mathrm{p}=0.041)$.

As for denial, assessments of psychiatric caseness (using the GHQ-28 questionnaire) were limited to subjects aged 15 yrs or more; the mean scores being 5.3 for death cases and 5.7 for NFA cases (Mann-Whitney; $\mathrm{p}=0.846$ ).

Based on all of the available evidence, the panel concluded that $86 \%$ of the death cases $(n=77)$ and $88 \%$ of NFA cases $(n=153)$ had psychosocial features which could have contributed to their asthma episode $(\mathrm{p}=0.739)$.
For tobacco use. The histories of death cases $(\mathrm{n}=71)$ and NFA cases $(\mathrm{n}=127)$ were similar, with 45 and $52 \%$, respectively, being smokers or ex-smokers $(\mathrm{p}=0.434)$, and 14 and $19 \%$, respectively, being current smokers $(\mathrm{p}=0.506)$.

\section{Asthma features}

No significant intergroup differences were found for asthma severity ratings or effects on work or school attendance (table 1). Whilst objective evidence of fixed airflow obstruction tended to be more common for death cases, this was not significant $(\mathrm{p}=0.115)$, nor was it in the regression analysis after age-sex adjustment $(\mathrm{p}=0.741)$. Symptom histories suggested that more death cases than NFA cases had experienced frequent symptoms in the three months prior to the last episode, but this was not a significant predictor in the regression analysis $(\mathrm{p}=0.311)$. Whilst death cases were found to have suffered from asthma for a longer duration than NFA cases, this was a function of their older age and was not significant when adjusting for age and sex in the logistic regression $(\mathrm{p}=0.649)$.

Significant intergroup differences were evident for other features, however. Fewer death cases showed objective evidence of reversibility, as indicated by spirometry or peak-flow monitoring, and this was confirmed in the regression analysis $(\mathrm{p}=0.053)$. Regression analysis also confirmed that after age-sex adjustment, death cases were more likely to have other significant medical conditions $(\mathrm{p}=0.019)$. By comparison, NFA cases were reported to have shown a greater tendency towards unstable and deteriorating asthma symptoms during the past 12 months,

Table 1. - Features of asthma conditions of 80 cases dying of asthma and 154 having near-fatal attacks, as assessed from reports of near acquaintances and medical practitioners: South Australia, 1988-1991

\begin{tabular}{|c|c|c|c|}
\hline Feature & $\begin{array}{c}\text { Death } \\
\text { cases } \\
\%\end{array}$ & $\begin{array}{l}\text { Near-fatal } \\
\text { attack cases } \\
\%\end{array}$ & $\begin{array}{c}\mathrm{p} \\
\text { value }\end{array}$ \\
\hline \multicolumn{4}{|l|}{ Asthma severity } \\
\hline Mild & 5 & 7 & \\
\hline Moderate & $22(n=73)$ & $28(\mathrm{n}=148)$ & $0.260 *$ \\
\hline Severe & 73 & 65 & \\
\hline \multicolumn{4}{|l|}{ Objective evidence of: } \\
\hline Reversibility & $37(\mathrm{n}=79)$ & $51(\mathrm{n}=148)$ & $0.061^{\dagger}$ \\
\hline Fixed airflow obstruction & $24(n=78)$ & $15(n=142)$ & $0.115^{\dagger}$ \\
\hline \multicolumn{4}{|l|}{ Symptom history } \\
\hline None for $3 \mathrm{yrs}$ & 1 & 1 & \\
\hline None for 3 months & $1(\mathrm{n}=74)$ & $3(n=126)$ & $0.085^{*}$ \\
\hline In last 3 months less than weekly & 11 & 20 & \\
\hline at least weekly & 87 & 76 & \\
\hline \multicolumn{4}{|l|}{ Symptom progression in last 12 months } \\
\hline Improving & 3 & 2 & \\
\hline Stable & $52(n=64)$ & $33(n=95)$ & $0.014 *$ \\
\hline Unstable/deteriorating & 45 & 65 & \\
\hline Mean duration since age of onset yrs & $25.1(n=67)$ & $21.2(n=149)$ & $0.158 *$ \\
\hline $\begin{array}{l}\text { Asthma causing }>1 \text { week absence from } \\
\text { work/school/usual daily activities } \\
\text { (12 month period) }\end{array}$ & $57(\mathrm{n}=63)$ & $62(n=123)$ & $0.650^{\dagger}$ \\
\hline Presence of other significant medical conditions & $63(n=70)$ & $33(n=131)$ & $<0.001^{\dagger}$ \\
\hline
\end{tabular}

*: Mann-Whitney U-test; ${ }^{\dagger}$ : conventional Chi-squared test (one degree of freedom). n: number of cases where valid responses were obtained for each feature. 
which was also confirmed in the regression analysis $(\mathrm{p}=0.023)$.

\section{Responses to prior acute episodes}

Death and NFA cases had similar histories for: visits to hospital accident and emergency departments; hospital admissions; admissions to intensive care units; and episodes requiring assisted ventilation (table 2 ).

\section{Routine asthma management}

Choice of primary health care provider was similar, with $74 \%$ of death cases and $71 \%$ of NFA cases using general medical practitioners (table 3 ). However, death cases reportedly had made more visits to their doctors for asthma in the prior 12 months, and this was confirmed to be so after age-sex adjustment in the regression analysis $(\mathrm{p}=0.013)$.

When all aspects of clinical care were considered by the panel, a similar proportion of death $(28 \%)$ and NFA cases $(23 \%)$ was found to have received care of optimum quality. Whilst more death than NFA cases had been given a crisis plan, this was not found to be significant in the regression analysis $(\mathrm{p}=0.448)$. However, more death cases $(92 \%)$ than NFA cases $(80 \%)$ were reported to have been shown how to use an inhaler, and this was significant in the regression analysis $(p=0.014)$.

Whilst death cases were found in the univariate analysis to have had better self-management, this feature was agerelated and the difference was not significant after adjusting for age and sex in the regression analysis $(\mathrm{p}=0.471)$. Similarly, whilst death cases reportedly showed better compliance with prescribed medications, this was not significant in the regression analysis $(\mathrm{p}=0.944)$. Moreover, the use of peak-flow meters at home in the last three months appeared to be similar in the two groups (table 3).

\section{Use of medications}

Regular use. A higher proportion of death cases (92\%) $(n=76)$ used some type of asthma medication regularly, when compared with NFA cases $(79 \%)(n=151)\left(\chi^{2}{ }_{(1)}\right.$ $\mathrm{p}=0.019)$. The difference was confirmed after age-sex adjustment in the regression analysis $(\mathrm{p}=0.003)$.

More death cases than NFA cases reportedly used betaagonists. After adjusting for age and sex in the regression analysis, the following were found to be more common among the death group: 1) use of any beta-agonist $(\mathrm{p}=0.046) ; 2)$ use of nebulized beta-agonists (any) $(\mathrm{p}=0.016)$; and 3) use of beta-agonist plus theophylline $(\mathrm{p}=0.049)$ (table 4).

There was also a tendency for more death than NFA cases to use a bronchodilator (beta-agonist or theophylline), together with an inhaled corticosteroids or cromoglycate, plus oral corticosteroids (table 4), but these differences were not significant in the regression analysis $(\mathrm{p}>0.200)$.

Symptomatic use. More death cases $(92 \%)(n=77)$ were found to increase their use of some type of asthma medication with increased symptoms, when compared with NFA cases $(84 \%)(n=152)\left(\chi^{2}{ }_{(1)} p=0.109\right)$. This was confirmed after age-sex adjustment in the regression analysis $(\mathrm{p}=0.017)$. However, differences were not found by type of medication (table 5).

Purchasing. There was no significant difference between the proportions of death cases $(n=61)$ and NFA cases $(n=123)$ who were reported to have purchased beta-agonists directly from a pharmacy rather than on prescription, 16 and $24 \%$, respectively, $(\mathrm{p}=0.352)$. Whilst fewer death cases $(24 \%)$ than NFA cases $(42 \%)$ were found to have made repeat purchases of prescribed items without further medical consultation $\left(\chi_{(1)}^{2}=4.7 ; \mathrm{p}=0.030\right)$, this was not significant after age-sex adjustment in the logistic regression $(\mathrm{p}=0.215)$.

Table 2. - Responses to past acute asthma episodes by 80 cases dying of asthma and 154 having near-fatal attacks, as assessed from reports of near acquaintances: South Australia, 1988-1991

\begin{tabular}{lrrr}
\hline Responses & $\begin{array}{c}\text { Death } \\
\text { cases }\end{array}$ & $\begin{array}{c}\text { Near-fatal } \\
\text { attack cases }\end{array}$ & $\begin{array}{c}\mathrm{p} \\
\text { value }\end{array}$ \\
\hline $\begin{array}{l}\text { Mean number of visits to hospital accident and } \\
\text { emergency department per subject }\end{array}$ & & & \\
$\quad$ Last 12 months & $0.4(\mathrm{n}=71)$ & $0.5(\mathrm{n}=125)$ & $0.291^{*}$ \\
$\quad$ Last month & $0.1(\mathrm{n}=77)$ & $0.1(\mathrm{n}=151)$ & $0.537^{*}$ \\
Visiting hospital accident and emergency & & & \\
department \% & $15(\mathrm{n}=71)$ & $22(\mathrm{n}=125)$ & $0.394^{\dagger}$ \\
$\quad$ Last 12 months & $4(\mathrm{n}=77)$ & $6(\mathrm{n}=151)$ & $0.755^{\$}$ \\
$\quad$ Last month & $80(\mathrm{n}=74)$ & $81(\mathrm{n}=131)$ & $0.982^{\dagger}$ \\
Hospital admission \% & $39(\mathrm{n}=71)$ & $45(\mathrm{n}=125)$ & $0.562^{\dagger}$ \\
$\quad$ Ever & $15(\mathrm{n}=71)$ & $11(\mathrm{n}=125)$ & $0.520^{\dagger}$ \\
$\quad$ Last 12 months & $24(\mathrm{n}=67)$ & $25(\mathrm{n}=122)$ & $0.955^{\dagger}$ \\
Last month & $17(\mathrm{n}=64)$ & $17(\mathrm{n}=125)$ & $0.890^{\dagger}$ \\
Admission to an intensive care unit (ever) $\%$ &
\end{tabular}

*: Mann-Whitney U-test; ${ }^{\dagger}$ : conventional Chi-squared test (one degree of freedom); $\$$ : Fisher's Exact Test. n: number of cases where valid responses were obtained for each item. 
Table 3. - Features of routine asthma management of 80 cases dying of asthma and 154 having near-fatal attacks, as assessed from reports of near acquaintances and medical practitioners: South Australia, 1988-1991

\begin{tabular}{|c|c|c|c|}
\hline Features & $\begin{array}{l}\text { Death } \\
\text { cases }\end{array}$ & $\begin{array}{l}\text { Near-fatal } \\
\text { attack cases }\end{array}$ & $\begin{array}{c}\mathrm{p} \\
\text { value }\end{array}$ \\
\hline \multicolumn{4}{|l|}{ Primary care provider $\%$} \\
\hline General medical practitioner & 74 & 71 & \\
\hline Specialist physician & 11 & 18 & \\
\hline Hospital clinic staff & $4(n=74)$ & $1(n=130)$ & $0.363^{\#}$ \\
\hline Community health centre staff & 4 & 3 & \\
\hline Other & 7 & 8 & \\
\hline \multicolumn{4}{|l|}{ Mean number of visits to doctor per subject } \\
\hline Last 12 months & $17.9(n=58)$ & $10.2(n=126)$ & $0.004 *$ \\
\hline Last month & $1.4(n=61)$ & $1.1(n=123)$ & $0.254 *$ \\
\hline \multicolumn{4}{|l|}{ Visiting a doctor \% } \\
\hline Last 12 months & $97(n=58)$ & $95(n=126)$ & $1.000^{\$}$ \\
\hline Last month & $69(n=61)$ & $57(\mathrm{n}=123)$ & $0.161^{\dagger}$ \\
\hline Appropriate crisis plan provided $\%$ & $63(n=72)$ & $51(n=150)$ & $0.130^{\dagger}$ \\
\hline Used a peak-flow meter at home \% & $31(n=64)$ & $38(n=124)$ & $0.458^{\dagger}$ \\
\hline $\begin{array}{l}\text { Had a lung-function test (from general } \\
\text { practitioner) } \%\end{array}$ & $35(n=69)$ & $41(n=98)$ & $0.530^{\dagger}$ \\
\hline $\begin{array}{l}\text { Had a lung-function test (general or } \\
\text { specialist practitioner) } \%\end{array}$ & $72(n=74)$ & $79(n=139)$ & $0.288^{\dagger}$ \\
\hline Generally took medication as prescribed $\%$ & $69(n=62)$ & $58(\mathrm{n}=126)$ & $0.176^{\dagger}$ \\
\hline Clinical care regarded as optimum $\%$ & $28(n=78)$ & $23(n=151)$ & $0.501^{\dagger}$ \\
\hline \multicolumn{4}{|l|}{ Self-management $\%$} \\
\hline good & 38 & 22 & \\
\hline adequate & $9(n=74)$ & $11(n=150)$ & $0.022 *$ \\
\hline poor & 53 & 67 & \\
\hline
\end{tabular}

*: Mann-Whitney U-test; ${ }^{\dagger}$ : conventional Chi-squared test (one degree of freedom); ${ }^{\$}$ : Fisher's Exact Test; \#: conventional Chi-squared test (four degrees of freedom). n: number of cases where valid responses were obtained for each feature.

Table 4. - Medications used regularly during the past 12 months by 80 cases dying of asthma and 154 having near-fatal attacks, as assessed from reports of near acquaintances: South Australia, 19881991

\begin{tabular}{|c|c|c|c|}
\hline Medications & $\begin{array}{l}\text { Death } \\
\text { cases } \\
\%\end{array}$ & $\begin{array}{l}\text { Near-fatal } \\
\text { attack cases } \\
\%\end{array}$ & $\underset{\text { value }}{\mathrm{p}}$ \\
\hline Beta-agonists (any) & $86(n=80)$ & $77(\mathrm{n}=154)$ & $0.116^{\dagger}$ \\
\hline Nebulized beta-agonists (any) & $39(\mathrm{n}=80)$ & $22(n=154)$ & $0.011^{\dagger}$ \\
\hline $\begin{array}{l}\text { Beta-agonists without accompanying } \\
\text { corticosteroids }\end{array}$ & $53(n=80)$ & $45(n=154)$ & $0.327^{\dagger}$ \\
\hline Theophylline & $49(n=80)$ & $49(n=154)$ & $0.896^{\dagger}$ \\
\hline $\begin{array}{l}\text { Theophylline without corticosteroids } \\
\text { or cromoglycate }\end{array}$ & $38(n=80)$ & $37(\mathrm{n}=154)$ & $0.945^{\dagger}$ \\
\hline Inhaled disodium cromoglycate & $6(n=80)$ & $8(n=154)$ & $0.735^{\dagger}$ \\
\hline Inhaled corticosteroids & $44(n=80)$ & $38(n=154)$ & $0.506^{\dagger}$ \\
\hline Oral corticosteroids & $26(n=80)$ & $16(n=154)$ & $0.098^{\dagger}$ \\
\hline Beta-agonists plus theophylline & $86(n=80)$ & $77(n=154)$ & $0.143^{\dagger}$ \\
\hline $\begin{array}{l}\text { Bronchodilator (beta-agonists or } \\
\text { theophylline) plus inhaled corticosteroid } \\
\text { or cromoglycate }\end{array}$ & $48(n=80)$ & $44(n=154)$ & $0.657^{\dagger}$ \\
\hline $\begin{array}{l}\text { Bronchodilator (beta-agonist or } \\
\text { theophylline) plus inhaled corticosteroid } \\
\text { or cromoglycate plus an oral } \\
\text { corticosteroid }\end{array}$ & $18(n=80)$ & $10(n=154)$ & $0.134^{\dagger}$ \\
\hline $\begin{array}{l}\text { Bronchodilator (beta-agonist or } \\
\text { theophylline) plus an oral corticosteroid } \\
\text { but no inhaled corticosteroid } \\
\text { or cromoglycate }\end{array}$ & $9(n=80)$ & $6(n=154)$ & $0.715^{\dagger}$ \\
\hline
\end{tabular}


Table 5. - Medications used with increased symptoms during the past 12 month by 80 cases dying of asthma and 154 having near-fatal attacks, as assessed from reports of near acquaintances: South Australia, 1988-1991

\begin{tabular}{lccc}
\hline Medications & $\begin{array}{c}\text { Death } \\
\text { cases } \\
\%\end{array}$ & $\begin{array}{c}\text { Near-fatal } \\
\text { attack cases } \\
\%\end{array}$ & $\begin{array}{c}\mathrm{p} \\
\text { value }\end{array}$ \\
\hline Beta-agonists (any) & $88(\mathrm{n}=80)$ & $82(\mathrm{n}=154)$ & $0.417^{\dagger}$ \\
Nebulizer beta-agonists (any) & $48(\mathrm{n}=80)$ & $39(\mathrm{n}=154)$ & $0.264^{\dagger}$ \\
Theophylline & $6(\mathrm{n}=80)$ & $8(\mathrm{n}=154)$ & $0.735^{\dagger}$ \\
Inhaled corticosteroids & $6(\mathrm{n}=80)$ & $7(\mathrm{n}=154)$ & $0.987^{\dagger}$ \\
Oral corticosteroids & $21(\mathrm{n}=80)$ & $20(\mathrm{n}=154)$ & $0.976^{\dagger}$ \\
\hline
\end{tabular}

\section{Final episodes}

Of the death cases $(n=79), 49 \%$ were found to have experienced acute progressive respiratory distress, $32 \%$ a sudden collapse, and 5\% to have died whilst receiving palliative care, whereas $14 \%$ were found dead. The ratio of acute progressive respiratory distress to sudden collapse of $4.0: 1$ for NFA cases $(n=154)$ was much higher than the corresponding ratio of $1.6: 1$ for death cases $(n=64)$, and the difference was significant in the regression analysis after age-sex adjustment ( $\mathrm{p}=0.005$ ).

Ready access to acute and general medical care applied to over $90 \%$ of subjects, but $56 \%$ of death cases $(n=64)$ and $58 \%$ of NFA cases $(n=154)$ were found to have delayed seeking medical care. Undue delay in receiving this care was found for $28 \%$ of death cases $(n=65)$ and $10 \%$ of NFA cases $(n=153)$, and this was significant after age-sex adjustment in the regression analysis $(\mathrm{p}=0.003)$.

More of the death cases $(n=70)$ than NFA cases $(n=153)$ were considered to have experienced appropriate helpseeking from close acquaintances, the respective percentages being 71 and $50 \%\left(\chi_{(1)}^{2}=8.4 ; p=0004\right)$, but this feature was strongly age-related and the difference was not statistically significant in the logistic regression $(\mathrm{p}=0.114)$.

\section{Preventability}

Panel assessments of this aspect varied $\left(\chi_{(3)}^{2}=26.4\right.$; $\mathrm{p}<0.001)$, the respective percentages for death cases $(n=79)$ and NFA cases $(n=153)$ being: 1$)$ definitely preventable 22 and $8 \%$; 2) probably preventable 41 and
$75 \%$; 3) probably not preventable 28 and $11 \%$; and 4) definitely not preventable 10 and $6 \%$. Notably, $62 \%$ of deaths were considered definitely or probably preventable, compared with $83 \%$ of NFA cases. More death cases $(n=75)$ than NFA cases $(n=151)$ were considered to be end-stage (17 and 3\%, respectively), and this difference was significant in the regression analysis after age-sex adjustment $(\mathrm{p}=0.034)$.

Table 6 indicates that there was little difference between preventable (definitely or probably) death cases and NFA cases with regard to the proportion who delayed seeking medical care at the time of the final episode. Similarly, there was little difference observed in the quality of their prior clinical care or self-management. Whilst family and self help-seeking actions at the time of the final episode tended to be more appropriate amongst the death cases, the difference was not statistically significant after age-sex adjustment in the regression analysis $(\mathrm{p}=0.148)$. However, death cases were more likely to have experienced a delay in actually receiving medical care during the final episode, and this difference was confirmed after age-sex adjustment $(\mathrm{p}<0.001)$. Also, the regression analysis indicated that, after age-sex adjustment, death cases had less ready access to acute medical care $(p=0.032)$.

\section{Discussion}

This study shows that asthmatics dying from asthma share many important similarities with those asthmatics who survive a near-fatal attack. This applies to: the severity of their asthma; the frequency of asthma symptoms;

Table 6. - Features of 49 cases dying of asthma, and 127 having near-fatal attacks, where these outcomes were assessed from reports of near acquaintances and medical practitioners to be definitely or probably preventable: South Australia, 1988-1991

\begin{tabular}{lccc}
\hline Feature & $\begin{array}{c}\text { Death } \\
\text { cases } \\
\%\end{array}$ & $\begin{array}{c}\text { Near-fatal } \\
\text { attack cases } \\
\%\end{array}$ & $\begin{array}{c}\mathrm{p} \\
\text { value }\end{array}$ \\
\hline Delay receiving medical care & $39(\mathrm{n}=44)$ & $13(\mathrm{n}=127)$ & $<0.001^{\dagger}$ \\
Delay seeking medical care & $73(\mathrm{n}=45)$ & $64(\mathrm{n}=127)$ & $0.326^{\dagger}$ \\
Medical care not readily available & $20(\mathrm{n}=49)$ & $11(\mathrm{n}=127)$ & $0.167^{\dagger}$ \\
Routine self-management not adequate & $63(\mathrm{n}=49)$ & $72(\mathrm{n}=127)$ & $0.314^{\dagger}$ \\
Appropriate crisis plan not available & $43(\mathrm{n}=49)$ & $54(\mathrm{n}=127)$ & $0.270^{\dagger}$ \\
Routine clinical care not regarded as & $86(\mathrm{n}=49)$ & $83(\mathrm{n}=127)$ & $0.795^{\dagger}$
\end{tabular}
optimum

$\dagger$ : conventional Chi-squared test (one degree of freedom). n: number of cases where valid responses were obtained for each feature. 
the impact of asthma on school or work attendance; history of asthma episodes leading to visits to hospital accident and emergency departments, general hospital admissions and admission to intensive care units; the type of primary health care provider; history of lungfunction testing; use of crisis plans; compliance with prescribed medications; and quality of medical management. Help-seeking behaviour during the fatal or nearfatal episode appeared to be similar, and history of previous psychiatric consultation and levels of psychiatric caseness were also similar.

The asthma death and NFA cases included in the present study were not similar in all respects, however. NFA cases tended to be younger, to include more males, to be less likely to have concurrent medical conditions, to be more likely to have high levels of denial, to have made fewer doctor visits for asthma in the 12 months prior to the attack, and to have made less use of asthma medications in general.

The levels of asthma severity found in this study were similar to those found in previous studies; $73 \%$ of asthma death cases and $65 \%$ of NFA cases were classified as having severe asthma, compared with $65 \%$ who were assessed as having severe asthma in the Victorian asthma mortality study [2]. In the present study, 39\% of asthma death cases and $45 \%$ of NFA cases were reported as having been admitted to hospital in the preceding 12 months, compared with $39 \%$ of cases reported to have been admitted in the preceding 12 month period in both the New Zealand and Victorian asthma mortality studies $[2,3]$. CRANE et al. [15] report that a history of admission for asthma in the preceding 12 months is the strongest single indicator of risk for subsequent death from asthma, and is also an indicator of subsequent risk for readmission.

Town et al. [16] identified the utility of an asthma management plan which incorporates peak expiratory flow monitoring. The Victorian asthma mortality study reported that $65 \%$ of cases $(n=193)$ had been provided with an appropriate asthma management plan [2], compared with $37 \%$ of asthma death cases and $49 \%$ of NFA cases in the present study. Only $31 \%$ of asthma death cases and $38 \%$ of NFA cases were reported as having used a peak flow meter at home, which is not significantly different from the proportion (31\%) previously reported amongst asthmatics attending accident and emergency departments in 1992 [17]. Only 13 of 163 cases were reported to have had a peak expiratory flow meter in the Victorian asthma mortality study performed in 1986 [2].

Prior medical management was assessed as optimal in only $25 \%$ of asthma death and NFA cases combined, with no significant difference between the two groups, on the basis of a consensus opinion of a reviewing committee. However, the perception of the quality of the medical management was extremely difficult to distinguish, from the quality of personal asthma management. Individual self-management was assessed as poor for $53 \%$ of asthma death cases and $67 \%$ of NFA cases. However, when the analysis was restricted to subjects aged less than $60 \mathrm{yrs}$, similar levels of poor self-management were seen for both groups. Reported compliance with prescribed medication from general practitioner reports was similar for the two groups (69 and 58\%, respectively). Similar levels of poor self-management were reported from the first case-control study of asthma death from New Zealand [5]. The British Thoracic Association investigation into asthma deaths assessed compliance as having been adequate in $69 \%$ of 90 cases, and that deterioration in asthma control had not been appreciated by managing doctors for $63 \%$ of cases, with supervision being classified as satisfactory for only two of 90 cases [4].

In the present study, 39\% of asthma death cases and $22 \%$ of NFA cases used regular nebulized beta-agonist therapy, compared with $28 \%$ of cases in the New Zealand asthma mortality study [3]. It is unclear whether a possible relationship between regular use of beta-agonists and increased morbidity is a class effect relevant to the use of all beta-agonists [18], a function of the potency of the preparation [19], or a function of the particular type of beta-agonist used [20]. That $53 \%$ of asthma death cases and $45 \%$ of NFA cases in the present study were regularly using beta-agonists without concomitant preventive medication gives cause for concern. The corresponding figure for the Victorian asthma mortality study was $41 \%$ [2]. Regular use of oral corticosteroids was reported for $26 \%$ of the asthma death and $16 \%$ of the NFA cases, with a figure of $16 \%$ also applying in the Victorian asthma mortality study [2], compared with $42 \%$ in the New Zealand study from the early $1980 \mathrm{~s}$, and $69 \%$ in the British study from the late 1970s [3, 4].

Reportedly, $16 \%$ of asthma death cases and $24 \%$ of NFA cases had purchased medications (inhaled betaagonists) directly from the pharmacist without a doctor's prescription. Asthmatics who purchase beta-agonists directly from the pharmacist have been shown to be less likely to consult with family doctors and also less likely to use prescription-only medication [21]. The high rate of repeat purchase of asthma medication on prescription without further medical consultation, as observed for asthma death (24\%) and NFA cases (42\%), suggests that an opportunity for regular review and education regarding appropriate asthma treatment is not being utilized for asthmatics who have clearly experienced high levels of prior morbidity due to asthma.

Delay in seeking medical care was a feature of the final event for $56 \%$ of asthma deaths and $58 \%$ of NFA cases. Delay receiving medical care was more common in the asthma death group than the NFA group. Amongst those cases where the final event was considered either definitely or probably preventable, delay in actually receiving medical care and less ready access to acute medical care distinguished death cases from NFA cases. Asthma education will need to provide asthmatics with skills to recognize deteriorating control of asthma, and with appropriate strategies to manage the deterioration. At present, many asthmatics appear to just increase the use of inhaled beta-agonist therapy, adopting a "wait and see" approach and hoping the situation will improve. It is of concern that in response to increased asthma symptoms only $20 \%$ of asthma death and NFA cases were reported to have increased use of oral corticosteroid medication in the prior 12 months, whilst over $80 \%$ of cases in both groups had increased the use of beta-agonists. 
Overall, $22 \%$ of asthma deaths in the present study were assessed as definitely having preventable factors associated; and $8 \%$ of the NFA cases were so assessed, compared with $37 \%$ of 126 asthma death cases which were assessed as definitely preventable in the Victorian study [2]. Almost two-thirds (62\%) of asthma death cases in the present study were considered definitely or probably preventable, compared with $61 \%$ of 271 cases in the New Zealand asthma mortality study [3], and $86 \%$ of 90 cases in the British study [4]. A higher proportion of NFA cases $(83 \%)$ was assessed as having preventable factors definitely or probably present, possibly reflecting the lower incidence of end-stage asthma in this younger group. This study identifies high levels of denial and prior psychiatric morbidity both in asthmatics dying of asthma and suffering a near-fatal attack of asthma, together with poor quality of personal and medical management of asthma. These are factors which should be addressed in future intervention studies, to reduce the risk of adverse outcomes from asthma in this high risk group who already have high levels of contact with the medical care system.

Although NFA and death cases appear not to be synonymous groups, it is clear that they are similar in many respects. Indeed, it is possible that some of the "significant" differences found between these groups could have occurred by chance in response to multiple testing. We conclude that more emphasis should be placed on studies of near-fatal asthma cases in the future. Through case "self-reporting", more accurate and detailed information should be obtainable to indicate how both near-fatal and fatal asthma episodes might be prevented.

We conclude that asthmatics who survive a near-fatal asthma episode share many important features with asthmatics who die of asthma, and should be subjected to more intensive research to indicate how asthma morbidity and mortality may be prevented.

Acknowledgements: This study was conducted under the auspices of the South Australian branch of the Thoracic Society of Australia and New Zealand, and sponsored by the Asthma Foundation of South Australia, The Faculty of Medicine of the University of Adelaide and the National Health and Medical Research Council of Australia. Financial support was obtained from the following pharmaceutical companies: Astra Pharmaceuticals Pty Ltd, Boehringer Ingelheim Pty Ltd, Glaxo Australia Pty Ltd and Fisons Pharmaceuticals Pty Ltd.

\section{References}

1. Sears MR. Trends in asthma mortality - New Zealand and international experience. In: Ruffin RE, ed. Asthma Mortality. Proceedings of the Second National Asthma Epidemiology Workshop. Sydney, Excerpta Medica, 1990; pp. 1-3.

2. Robertson CF, Rubinfeld AR, Bowes G. Deaths from asthma in Victoria: a twelve month survey. Med J Aust 1990; 152: 511-517.

3. Sears MR, Rea HH, deBoer G, et al. Asthma mortality in New Zealand: a two year national study. NZ Med J 1985; 98: 271-275.

4. British Thoracic Association. Deaths from asthma in two regions of England. Br Med J 1982; 285: 12511255.

5. Rea HH, Scragg R, Jackson R, et al. A case-control study of deaths from asthma. Thorax 1987; 41: 833-839.

6. Yellowlees PM, Ruffin RE. Psychological defences and coping styles in patients following a life-threatening attack of asthma. Chest 1989; 95: 1298-1303.

7. Campbell DA, McLennan G, Coates JR, et al. Nearfatal asthma attacks: the reliability of descriptive information collected from close acquaintances. Thorax (In press).

8. Pilowsky I, Spence ND. Manual for the Illness-Behaviour Questionnaire. Adelaide, University of Adelaide Press, 1981.

9. Goldberg D. Use of the general health questionnaire (GHQ) in clinical work. Br Med J 1986; 293: 1188-1189.

10. Armitage P, Berry G. Statistical methods in medical research. Oxford, Blackwell Scientific Publications, 1987; pp. 411-416.

11. Armitage P, Berry G. Statistical methods in medical research. Oxford, Blackwell Scientific Publications, 1987; pp. 127-129.

12. Armitage P, Berry G. Statistical methods in medical research. Oxford, Blackwell Scientific Publications, 1987; pp. 387-393.

13. SPSS/PC+ 4.0. SPSS Inc., Chicago, 1990.

14. Hosmer DW, Lemeshow S. Applied logistic regression. New York, John Wiley and Sons, 1989; pp. 132-133.

15. Crane J, Pearce N, Burgess C, et al. Markers of risk of readmission in the 12 months following a hospital admission for asthma. Int J Epidemiol 1992; 21: 737-744.

16. Town I, Kwong T, Holst P, Beasley R. Use of a management plan for treating asthma in an emergency department. Thorax 1990; 45: 702-706.

17. Young L, Bauman A, McGirr J, et al. A multicentre study of asthma attendances at accident and emergency departments. Proceedings of the 1992 Annual Scientific Conference of the Thoracic Society of Australia and New Zealand. Sydney, Thoracic Society of Australia and New Zealand, 1992.

18. Spitzer WO, Suissa S, Ernst P, et al. The use of betaagonists and the risk of death and near-death from asthma. $N$ Eng J Med 1992; 326: 1161-1165.

19. Wong CS, Pasvord ID, Williams J, Britton JR, Tattersfield AE. Bronchodilator, cardiovascular and hypokalemic effects of fenoterol, salbutamol and terbutaline in asthma. Lancet 1990; 336: 1396-1399.

20. Crane J, Pearce N, Flatt A, et al. Prescribed fenoterol and death from asthma in New Zealand, 1981-1983: a case-control study. Lancet 1989; i: 917-922.

21. Henry DA, Sutherland D, Francis L, and the Newcastle Retail Pharmacy Research Group. The use of nonprescription salbutamol inhalers by asthmatic patients in the Hunter Valley, New South Wales. Med J Aust 1989; 150: 445-449. 